\title{
AMPLITUDES OF P, PP, AND S AND MAGNITUDE OF SHALLOW EARTHQUAKES*
}

\author{
By B. Gutenberg
}

THE DETERMINATION of the magnitude of distant earthquakes has been based thus far on the amplitudes of surface waves having periods of about 20 seconds: This method can be applied only to shallow earthquakes. The determination of the magnitude of shocks with a focal depth in excess of about $30 \mathrm{~km}$. must be based on the amplitudes of the body waves. Before this can be accomplished, the relationship between amplitudes of body waves and the magnitude of shallow shocks must be studied. In the present paper the amplitudes of $\mathrm{P}, \mathrm{PP}$, and $\mathrm{S}$, as a function of the magnitude $M$ and the distance, $\Delta$, are investigated as a first step in this direction.

The expression for the calculation of the ground displacement during a single body wave as a function of $\Delta$ is

$$
K T N \sqrt{E_{1}}
$$

where

$$
N=Q \sqrt{\left(F_{1} F_{2} \ldots F_{n}\right) a \frac{\sin i_{h} d i_{h} / d \Delta}{\sin \Delta \cos i_{0}}}
$$

The equation is based on the original theory of Zoeppritz (Zoeppritz, Geiger, and Gutenberg, 1912). The quantities involved in (2) have been discussed by Gutenberg $(1944 a) . K$ depends on the fraction of the energy $E_{1}$ passing into the wave under consideration. It has three distinct values, for waves starting respectively as $\mathrm{P}, \mathrm{SH}$, and SV. $T$ is the period of the observed wave. $Q$ has different values for the horizontal and the vertical components ( $u$ and $w$, respectively) of the total ground displacement; we indicate by $U$ the horizontal and by $W$ the vertical component of $N$.

From expression (1) it follows that for one single wave

$$
1 / 2 \log E_{1}=\log u-\log K-\log T-\log U
$$

A similar equation holds for the vertical component. Investigations by Gutenberg and Richter (1942, eq. 35, p. 180) gave the following equation connecting the total energy $E$ and the magnitude $M$ of a shallow earthquake

$$
\log E=11.3+1.8 M
$$

Supposing that the duration $t$ of a given phase increases with the distance $\Delta$ proportionally to $T$, we have

$$
E=q t E_{\mathrm{r}} / T=q t_{0} E_{1} / T_{0}
$$

where the subscripts zero refer to the source and $q$ is the fraction of the energy going into the phase considered; $q$ is assumed to be constant. From Gutenberg and Richter (1942, eq. 28 and 32 ), in transverse waves $t_{0} / T_{0}$ should not depend appreciably on the magnitude. Supposing that this is approximately correct for all waves, the combination of (3), (4), and (5) shows that in a given earthquake

$$
L=0.9 M-\log u+\log T+\log U
$$

* Manuscript received for publication August 21, 1944. 
should have a nearly constant value for all waves starting as $\mathrm{P}$ waves, another for all starting as SV, and a third for those starting as SH. These constants $L$ depend on the fractions of energy distributed among the fundamental types of waves. For practical purposes it has been assumed that there is one constant $C$ in all shocks for $\mathrm{P}$ waves and another for all $\mathrm{S}$ waves (combined $\mathrm{SV}$ and $\mathrm{SH}$ ) given by

$$
C=Y-0.1(M-7)+\log T
$$

where

$$
Y=M-\log u+\log U=M-\log w+\log W
$$

As most shocks for which the amplitudes of body waves at distant stations can be studied have magnitudes between 6 and 8 , the absolute value of $0.1(M-7)$ rarely exceeds 0.1 .

One way to use equation (7) would be to tabulate observed ground amplitudes ( $u$, horizontal, or $w$, vertical) as a function of $\Delta$ together with their respective periods $T$ for shocks of known magnitudes $M$ and to calculate for the horizontal components

$$
A=C-\log U=M-\log u-0.1(M-7)+\log T
$$

and a similar expression for the vertical components. The mean curves of $A$ as a function of $\Delta$ can then be used in the calculation of $M$, if $u$ or $w$ and $T$ at a given distance are known from seismograms. However, it was considered preferable first to calculate $U$ and $W$ from equation (2) and use the observations to find the constants $C$ as well as corrections to the calculated $U$ and $W$, since this gives a valuable check on the theory, and then to set up tables for $A$ as a final step.

Equation (2) contains the absorption factor

$$
a=e^{-k D}
$$

for body waves. The absorption coefficient $k$ is here assumed to be constant along the whole path $D$ of the waves. The best way to find $k$ is to use amplitudes of two waves $x$ and $y$ on the same seismogram which have traveled over paths with as different length $D$ as possible. Good results, therefore, are expected if $\mathrm{P}, \mathrm{P}^{\prime} \mathrm{P}^{\prime}$, and $\mathrm{P}^{\prime} \mathrm{P}^{\prime} \mathrm{P}^{\prime}$ are used. If $H$ is the amplitude ratio of $x$ and $y$, calculated from equations (1) and (2) neglecting the absorption (for tables, see Dana, 1944) but including the effect of differences in the periods $T$, and $r$ the observed ratio, equations (1), (2), and (10) give

$$
k=2(\log H-\log r) /\left(D_{x}-D_{y}\right) \log e
$$

For observations, records of the short-period and long-period vertical Benioff

\begin{tabular}{|c|c|c|c|c|}
\hline Phases used & $\begin{array}{l}\text { Number of } \\
\text { observations }\end{array}$ & $\begin{array}{c}\text { Average } k \\
\text { per km. }\end{array}$ & $\begin{array}{l}\text { Stand } \\
\text { result }\end{array}$ & $\begin{array}{l}\text { error of: } \\
\text { one obser vation }\end{array}$ \\
\hline $\mathrm{P}^{\prime} \mathrm{P}^{\prime}$ and $\mathrm{P}$. & 56 & 0.00012 & 0.00001 & 0.00007 \\
\hline $\mathrm{P}^{\prime} \mathrm{P}^{\prime} \mathrm{P}^{\prime}$ and $\mathrm{P}$. & 37 & 0.00011 & 0.00001 & 0.00004 \\
\hline $\mathrm{P}^{\prime} \mathrm{P}^{\prime}$ and $\mathrm{P}^{\prime} \mathrm{P}^{\prime} \mathrm{P}^{\prime}$ & 17 & 0.00012 & 0.00003 & 0.00011 \\
\hline
\end{tabular}
instruments at Pasadena and its auxiliary stations and of the short-period verticals at Tucson, Arizona (courtesy of the U.S. Coast and Geodetic Survey), were used. Amplitudes of phases at distances within about $5^{\circ}$ of a focal point were not included in the measurements. The results are as follows: 
In general, measurements used for the last line were not included in calculations of the first two. The agreement among the three lines indicates that the difference between the absorption of $\mathrm{P}$ waves in the mantle of the earth and in the core is small. The resulting $k=0.00012$ equals that found previously for $\mathrm{G}$ waves (very long surface shear waves). It seems, therefore, that for all those earthquake waves

TABLE 1

Calculated Values of $U$ and $W$ (Equation 2) and Corrections as a Function of the Distance $\Delta$ in Degrees

\begin{tabular}{|c|c|c|c|c|c|c|c|c|}
\hline \multirow{3}{*}{$\Delta$} & \multicolumn{5}{|c|}{ Calculated values } & \multicolumn{3}{|c|}{ Corrections } \\
\hline & \multicolumn{2}{|c|}{$\mathrm{P}$} & \multicolumn{2}{|c|}{$\mathrm{PP}$} & \multirow{2}{*}{$\frac{\mathrm{s}}{U}$} & \multirow{2}{*}{$\frac{\mathrm{P}}{U \text { and } W}$} & \multirow{2}{*}{$\frac{\mathrm{PP}}{U \text { and } W}$} & \multirow{2}{*}{$\frac{\mathrm{s}}{U}$} \\
\hline & $U$ & $W$ & $U$ & $W$ & & & & \\
\hline 15. & +0.30 & +0.40 & $\ldots \ldots$ & $\ldots$ & +0.7 & -0.1 & $\ldots \ldots$ & -0.3 \\
\hline 20. & +0.12 & +0.24 & $\ldots$ & $\ldots \ldots$ & +0.5 & -0.4 & $\ldots \ldots$ & -0.2 \\
\hline 24. & -0.02 & +0.15 & & . & +0.3 & -0.4 & $\ldots \ldots$ & 0.0 \\
\hline 28. & -0.21 & 0.00 & & & +0.1 & -0.2 & $\ldots$ & +0.1 \\
\hline 32. & -0.43 & -0.19 & -0.3 & -0.1 & -0.1 & -0.1 & -0.4 & +0.2 \\
\hline 36. & -0.64 & -0.40 & -0.3 & -0.1 & -0.2 & 0.0 & -0.4 & +0.1 \\
\hline 40. & -0.82 & -0.57 & -0.4 & -0.2 & -0.4 & +0.2 & -0.2 & +0.1 \\
\hline 44. & -0.43 & -0.18 & -0.4 & -0.3 & -0.4 & -0.2 & -0.1 & +0.1 \\
\hline 48. & -0.55 & -0.27 & -0.5 & -0.3 & -0.2 & -0.2 & 0.0 & -0.1 \\
\hline 52. & -0.72 & -0.42 & -0.6 & -0.4 & -0.3 & -0.1 & +0.1 & -0.1 \\
\hline 56. & -0.85 & -0.51 & -0.6 & -0.4 & -0.4 & +0.1 & -0.2 & +0.1 \\
\hline 60. & -0.92 & -0.58 & -0.8 & -0.5 & -0.2 & +0.1 & -0.2 & -0.3 \\
\hline 64. & -0.80 & $-0.43^{\circ}$ & -0.9 & -0.7 & -0.3 & 0.0 & -0.1 & -0.4 \\
\hline 68. & -0.72 & -0.33 & -0.9 & -0.7 & -0.4 & -0.2 & 0.0 & -0.1 \\
\hline 72 & -0.82 & -0.41 & -1.1 & -0.8 & -0.9 & -0.2 & +0.1 & +0.1 \\
\hline 76. & -1.15 & -0.72 & -1.2 & -1.0 & -0.9 & 0.0 & +0.3 & +0.4 \\
\hline 80 & -1.05 & -0.57 & -1.2 & -1.0 & -0.8 & +0.2 & +0.3 & +0.2 \\
\hline $84 \ldots$ & -1.15 & -0.68 & -0.8 & -0.6 & -0.7 & +0.1 & -0.3 & +0.1 \\
\hline 88. & -1.30 & -0.77 & -0.9 & -0.6 & -0.5 & +0.1 & -0.2 & -0.1 \\
\hline 92 . & -1.10 & -0.58 & -0.9 & -0.6 & -0.4 & +0.1 & 0.0 & -0.3 \\
\hline $96 \ldots$ & -1.5 & -0.8 & -1.0 & -0.7 & -0.6 & +0.1 & +0.1 & -0.2 \\
\hline 100 . & -1.8 & -1.1 & -1.0 & -0.7 & -0.9 & +0.1 & 0.0 & 0.0 \\
\hline 120. & $\ldots \ldots$ & $\ldots$ & -1.3 & -1.0 & $\ldots$ & $\ldots$ & +0.2 & $\ldots$. \\
\hline 140. & $\ldots \ldots$ & & -1.1 & -0.7 & $\ldots$ & & +0.1 & 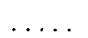 \\
\hline 160. & & & -1.3 & -0.8 & $\ldots$ & & +0.2 & \\
\hline 176. & $\ldots$ & $\ldots$ & -1.3 & -0.8 & $\ldots$ & 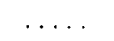 & +0.2 & $\ldots \ldots$ \\
\hline
\end{tabular}

which are not much affected by crustal layers the absorption is about the same. This is confirmed by the final findings with respect to the change of amplitudes of PP and S with distance. PP should show a systematic error in the calculated amplitudes, increasing with distance, if an incorrect value of $k$ is used. As the error in magnitudes calculated from PP at distances approaching $20,000 \mathrm{~km}$. apparently does not exceed \pm 0.2 on the average, it follows that the error in $k$ probably is within \pm 0.00005 per $\mathrm{km}$. Though this is a wider limit of error than those given above, it is important as an independent check not involving waves through the core. 
Equation (2) can now be used to calculate the components $U$ and $W$ of $N$. With the value of $k$ just found, $a$ can be calculated from equation (10); $F$ (for PP only) and $Q$ were taken from Gutenberg $(1944 a)$. It was assumed that $i_{0}=i_{h}$; and $i$ as a function of $\Delta$ was calculated from the travel times of Gutenberg and Richter (1939), assuming a velocity of $5.6 \mathrm{~km} / \mathrm{sec}$. for longitudinal and of $3.26 \mathrm{~km} / \mathrm{sec}$. for

TABLE 2

Corrections to be Adde to the Logaritem of the Ground Amplitudes of Bodx Waves in the Calculation of Earthquake Magnitudes of Teleseisms

(Last column, correction for the maximum, for comparison. $n=$ number of observations; $s=$ standard error of one observation; $e=$ standard error of the correction)

\begin{tabular}{|c|c|c|c|c|c|c|c|c|c|}
\hline \multirow{2}{*}{ Station } & \multicolumn{4}{|c|}{ Horizontal component } & \multicolumn{4}{|c|}{ Vertical component } & \multirow{2}{*}{$\begin{array}{l}\text { Correc- } \\
\text { tion } \\
\text { surface } \\
\text { waves }\end{array}$} \\
\hline & Correction & $n$ & $e$ & $s$ & Correction & $n$ & $e$ & $s$ & \\
\hline Alicante.... & -0.2 & 14 & 0.1 & 0.4 & $\ldots \ldots$ & . & $\ldots$ & . & $\ldots$ \\
\hline Almería.......... & -0.1 & 4 & 0.4 & 0.6 & +0.1 & 4 & 0.1 & 0.3 & $\ldots$ \\
\hline Belgrade......... & 0.0 & 15 & 0.1 & 0.3 & 0.0 & 9 & 0.2 & 0.1 & $\ldots$ \\
\hline Budapest.......... & -0.1 & 7 & 0.1 & 0.2 & $\ldots$ & . & $\ldots$ & $\therefore$ & $\therefore$ \\
\hline Cartuja............ & -0.1 & 38 & 0.1 & 0.6 & +0.1 & 30 & 0.1 & $0 . \frac{1}{4}$ & 0.0 \\
\hline Chicago (USCGS). & +0.1 & 7 & 0.2 & 0.5 & $\ldots$ & $\ldots$ & $\ldots$ & $\ldots$ & $\cdots$ \\
\hline Chiufeng........ & 0.0 & 5 & 0.2 & 0.4 & $\ldots \ldots$ & . & $\ldots$ & $\ldots$ & 0.0 \\
\hline De Bilt. . . . . . . . & -0.2 & 9 & 0.1 & 0.2 & $\ldots \ldots$ & $\ldots$ & $\ldots$ & $\ldots$ & -0.2 \\
\hline Fordham......... & +0.2 & 4 & 0.2 & 0.6 & $\ldots$. & . & $\ldots$ & $\ldots$ & $\cdots$ \\
\hline Göttingen. . . . . . & +0.2 & 94 & 0.04 & 0.4 & +0.2 & 57 & 0.05 & 0.4 & \\
\hline Hamburg. & -0.4 & 9 & 0.1 & 0.2 & $\ldots$ & . & .. & $\ldots$ & -0.2 \\
\hline Jena...... & +0.2 & 121 & 0.04 & 0.4 & +0.2 & 61 & 0.05 & 0.1 & $\cdots$ \\
\hline La Paz.......... & +0.2 & 60 & 0.05 & 0.4 & +0.3 & 40 & 0.07 & 0.4 & +0.1 \\
\hline Leipzig......... & -0.1 & 27 & 0.07 & 0.4 & $\ldots$ & . & $\cdots$ & $\ldots$ & -0.1 \\
\hline München...... & -0.3 & 9 & 0.1 & 0.3 & $\ldots \ldots$ & . & $\cdots$ & $\ldots$ & . \\
\hline Ottawa.......... & 0.0 & 7 & 0.1 & 0.2 & & . & $\ldots$ & $\ldots$ & 0.0 \\
\hline Paris. . & -0.3 & 6 & 0.1 & 0.2 & $\ldots \ldots$ & . & $\ldots$ & $\ldots$ & $\ldots$ \\
\hline Potsdam..... & -0.2 & 14 & 0.1 & 0.4 & $(+0.3)$ & 4 & 0.1 & 0.2 & 0.0 \\
\hline Riverview....... & +0.1 & 86 & 0.05 & 0.4 & +0.5 & 10 & 0.1 & 0.3 & +0.2 \\
\hline Tashkent... & -0.1 & 16 & 0.1 & 0.5 & $\ldots$ & . & $\ldots$ & $\ldots$ & +0.1 \\
\hline Toledo....... & -0.1 & 14 & 0.1 & 0.3 & $(-0.1)$ & 3 & 0.3 & 0.1 & 0.0 \\
\hline Wien........ & -0.2 & 9 & 0.1 & 0.3 & $\ldots$ & . & $\ldots$ & $\ldots$ & . \\
\hline Zi-ka-wei... & $(+0.1)$ & 4 & .0 .1 & 0.2 & $(+0.6)$ & 4 & 0.2 & 0.3 & +0.3 \\
\hline Zurich...... & -0.1 & 6 & 0.1 & 0.3 & $\ldots$ & . & $\ldots$ & $\ldots$ & $\cdots$ \\
\hline
\end{tabular}

transverse waves near the surface. Errors introduced by this assumption can scarcely affect the logarithm of the calculated amplitudes by more than 0.2 . Moreover, this error does not change very much with distance, and, consequently, affects the resulting constant $C$ in equation (7) more than the individual residuals in the calculation. However, it must be considered that for waves having periods of a very few seconds the wave length is definitely less than the thickness of the granitic layer, while for those with periods of 10 or more seconds it exceeds it. Thus, scattering of residuals may be increased by assuming the same angle of incidence at a given distance for waves with different periods. Characteristic calculated values of $U$ and $W$ for $\mathrm{P}, \mathrm{PP}$, and $\mathrm{S}$ (using $d i / d \Delta$ in degrees per degree) are given in table 1. 
Observations were taken from routine station bulletins, most of which are listed in table 2, and from publications of special measurements made for other purposes, including those of the San Francisco earthquake of 1906 (Reid, 1910), the South German earthquake of 1911 (Gutenberg, 1915), the Eureka earthquake of 1922 (Macelwane, 1923), the Tokyo earthquake of 1923 (Gutenberg, 1925), the Montana earthquake of 1925 (Byerly, 1926), and the Alaskan earthquake of 1927 (Sommer, 1931). The first two were not included in the calculation of residuals, as the magnitude of these shocks was not considered to be known accurately enough. From all other data, $C$ was found, using in equations (7) and (8) the magnitudes determined from surface waves, $T$ and $u$ (or $w$ ) as given in the reports, $\Delta$ from the determination of the epicenter considered best, and $U$ (or $W$ ) from table 1. As preliminary corrections of amplitudes (to be applied on account of instrumental inaccuracies and variability of ground at various stations), those found for the surface waves (Gutenberg, 1945) were used whenever possible. The following average values of $C$ resulted (number of data in table 3):

\begin{tabular}{c|c|c|c|c}
\hline \multicolumn{2}{c|}{$\mathrm{P}$} & \multicolumn{2}{|c|}{$\mathrm{PP}$} & $\mathrm{s}$ \\
\hline$U$ & $W$ & $U$ & $W$ & $U$ \\
\hline $6.34 \pm 0.03$ & $6.51 \pm 0.03$ & $6.34 \pm 0.03$ & $6.48 \pm 0.04$ & $6.29 \pm 0.03$ \\
\hline
\end{tabular}

Theoretically, the first four values should be equal; but the last may be different. Actually, the horizontal components of $\mathrm{P}$ and $\mathrm{PP}$ lead to the same value of $C$ within the limits of error, and the vertical components to another, about 0.15 greater. This is certainly within the systematic errors. Possibly, on the average, the vertical ground amplitudes were reported too small relative to the horizontal amplitudes by about 30 per cent (the antilog of -0.15 is 0.7 ). This would not be surprising, since most of the data for vertical amplitudes are based on records of mechanically recording instruments, some with rather small mass; frequently, the friction is not properly considered in calculating amplitudes from records of such instruments. On the other hand, the value of $C$ for the $\mathrm{S}$ waves is so close to that for $\mathrm{P}$ that one and the same constant $C$ was assumed for all waves. As in general only one decimal is used in the calculations, it was decided to take

$$
C=6.3
$$

and to take care of the differences, especially those for the vertical components, in the station corrections to be discussed below.

From the fact that $C$ is about equal for $\mathrm{P}$ and $\mathrm{S}$ waves, it follows that on the average the original energy in the longitudinal and transverse waves is roughly equal. Within observational errors this agrees with the earlier findings of Gutenberg (Geiger and Gutenberg, 1912, p. 665) that near the source both types of waves appear to have equal amplitudes. According to a hypothesis stated by Wiechert (Geiger and Gutenberg, 1912, footnotes on pp. 647 and 665), fracturing along a fault surface in a tectonic earthquake gives rise simultaneously to $\mathrm{P}$ and $\mathrm{S}$ waves which have initially identical amplitudes, periods, and energy. In their propagation 
both retain the same wave length, and thus their prevailing periods must be proportional to the reciprocals of the respective velocities (which would be about $1: 1.8$, in agreement with the observations).

The value of $C$ may be calculated also from records of local shocks. Gutenberg (1944b, eq. 2) found that in southern California shocks of magnitude 5 the following equation holds for $\mathrm{P}$ waves at epicentral distances between 50 and $500 \mathrm{~km}$.:

$$
\log b=2.0+\log U^{*}
$$

where $b$ is the horizontal trace amplitude which would be recorded by a standard Wood-Anderson torsion seismograph (free period 0.8 sec., magnification 2,800 , nearcritical damping) in the azimuth toward the source; $U^{*}$ is the expression $U$ used in the present paper, but with $d i / d \Delta$ measured in radians per $100 \mathrm{~km}$., and $\sin \Delta$ in the denominator of equation (2) replaced by $\Delta$ in $\mathrm{km}$. Consequently, we have

$$
\begin{aligned}
& \log U=\log U^{*}+1 / 2 \log (180 / \pi)-1 / 2 \log (111 / 100)+1 / 2 \log (20,000 / \pi) \\
& \log U=\log U^{*}+2.76
\end{aligned}
$$

Since the period of $\mathrm{P}$ is less than the free period of the instrument, for the horizontal ground displacement $u$ in microns

$$
\log u=\log b-0.45
$$

Introducing $\log b$ and $\log U^{*}$ in (13), we find

$$
\log U-\log u=1.2
$$

and, with $M=5$, from equation (8)

$$
Y=6.2
$$

The period of $\overline{\mathrm{P}}$ in a shock of magnitude 5 at an epicentral distance of $200 \mathrm{~km}$. is approximately 0.5 sec., and from equation (7), $C=6.1$. With the correction for $\mathrm{P}$ waves given by equation $(17), C=6.4$. In any case, the findings based on $\overline{\mathrm{P}}$ in the local shocks are in good agreement with the result $C=6.3$ from teleseismic data.

The ratio $\overline{\mathrm{S}} / \overline{\mathrm{P}}$ as calculated from observations seems to vary somewhat. In southern California earthquakes, the average difference $\log \overline{\mathrm{S}}-\log \cdot \overline{\mathrm{P}}$ is about 0.7 (Gutenberg, 1944b, table 4); however, in earthquakes originating on the Inglewood fault, $\log \overline{\mathrm{S}}-\log \overline{\mathrm{P}}$ was between 1.0 and 1.2 in all the six shocks studied, while in all other shocks this difference was between 0.4 and 0.8 . In the shocks of the first group several stations were near a nodal line for $\mathrm{P}$ waves (direction source-station nearly perpendicular to the fault), which may explain the relatively small $\mathbf{P}$ waves (Gutenberg, 1941); in such azimuths practically all the energy goes into the $S$ waves. In the South German earthquakes of 1911 and 1913 (Gutenberg, 1915) the corresponding differences were between 0.2 and 0.8 (three stations in the first, five in the second), with an average of 0.6 .

Theoretically, the ratio of $\mathrm{S} / \mathrm{P}$ depends on $T$ as well as $U$ (eq. 7 ). If Poisson's Ratio does not change with depth in the granitic layer, the only quantity in equation (2) which differs for $\overline{\mathrm{S}}$ and $\overline{\mathrm{P}}$ is $Q$. In an $\overline{\mathrm{S}} \mathrm{H}$ wave (which seems to have larger amplitudes than $\overline{\mathrm{S}} V$ ) $\log Q$ (and, consequently, $\log U$ ) exceeds that for the horizontal 
component of $\overline{\mathrm{P}}$ by about 0.2 on the average. Periods of $\mathrm{S}$ have been found, on the average, to be nearly twice those of $\mathrm{P}$. Therefore, for a shock in which originally the $P$ and $S$ waves have equal energy, $\log \overline{\mathrm{S}}-\log \overline{\mathrm{P}}$ should be about 0.4 or 0.5 . The actually observed values are on the average about 0.1 to 0.2 greater, which is within the limits of error; however, investigations of this relation are desirable. As a whole, the agreement between all available data from observations and the calculations (to a first approximation only) are better than should be expected.

From comparison between the average value of $C$ for a given station and the general average of 6.3 , station corrections can be calculated similar to those found for the maxima (Gutenberg, 1945, table 1). All data for P, PP, and S from the horizontal components were combined to form one correction, and the residuals for the vertical components of $\mathrm{P}$ and $\mathrm{PP}$ to form a second. Table 2 gives the results. The corrections found by using surface waves are added for comparison. For all, the largest negative corrections are for stations on unconsolidated water-saturated ground.

After application of the station corrections to the individually calculated values of $C$, the residuals relative to 6.3 were plotted as a function of the distance $\Delta$ for all five groups. The respective residuals for the horizontal and vertical components agree within the limits of error, and for calculations of averages for small ranges of $\Delta\left(2^{\circ}\right.$ to $5^{\circ}$, depending on the changes with $\Delta$ on the plot and the number of observations available) all residuals, horizontal and vertical, for $\mathrm{P}$ were combined to one set, and similarly all for $\mathrm{PP}$ to another. The resulting corrections, using the calculated averages as well as the plotted data for $\mathrm{P}, \mathrm{PP}$, and $\mathrm{S}$, are given in the last three columns of table 1 . The corrections for PP correspond fairly well to those for $\mathrm{P}$ at half the distance.

$\mathrm{P}$ and $\mathrm{PP}$ are characterized by persistent negative corrections at their beginning in table 1 (thirty-two observations out of forty for distances between $15^{\circ}$ and $29^{\circ}$ in P). They indicate that the observed amplitudes are smaller than those calculated from the travel-time curve. The most likely reason for this is that it was incorrectly assumed that the travel-time curve is an uninterrupted straight line up to about $\Delta=15^{\circ}$. However, there can be little doubt that in shallow shocks a shadow zone for $\mathrm{P}$ waves extends from about $5^{\circ}$ to $14^{\circ}$ or $15^{\circ}$ with a focal point (caustic) at the end. This focal point must be slightly higher than the assumed straight line, giving for the following part of the curve a smaller $d i / d \Delta$ than that assumed in the calculation. Possibly a sudden increase in velocity causing the much-discussed " $20^{\circ}$ discontinuity" (Byerly, 1926; Jeffreys, 1936, 1937; Gutenberg and Richter, 1939, p. 98) is also involved.

The most important corrections for the amplitudes of $\mathrm{S}$ are between $60^{\circ}$ and $80^{\circ}$. The following are calculated corrections $d$ of the values of $U$ for $S$ in table 1 :

\begin{tabular}{lrrrrrr} 
Distance, degrees $\ldots \ldots \ldots \ldots \ldots$ & $58-62$ & $63-67$ & $68-72$ & $73-75$ & $76-80$ & \multicolumn{1}{c}{$81-83$} \\
Correction $d \ldots \ldots \ldots \ldots \ldots \ldots$ & 0.3 & 0.3 & 0.05 & -0.3 & -0.3 & -0.1 \\
Standard error of $d \ldots \ldots \ldots \ldots$ & 0.1 & 0.1 & 0.06 & 0.05 & 0.06 & 0.06 \\
Number of observations....... & 13 & 41 & 19 & 27 & .32 & 30
\end{tabular}

They indicate that at distances near $60^{\circ}$ the travel-time curve of $\mathrm{S}$ is more curved than was assumed, and less curved near $75^{\circ}$. A detailed discussion of these problems requires inclusion of more data and of special studies, including amplitude ratios. 
The next step is to investigate how far the residuals depend on the magnitude of the shocks. As there is no systematic difference between the residuals of $\mathrm{P}$ and $\mathrm{PP}$, nor between their horizontal and their vertical components, all these residuals were

TABLE 3

Improvement in Standard Errors of One Determination of $C$ on Applying Successtre Corrections as Indicated in the Table

( $u=$ horizontal, $w=$ vertical component)

\begin{tabular}{|c|c|c|c|c|c|}
\hline \multirow{3}{*}{ All data available } & \multicolumn{5}{|c|}{ Standard errors } \\
\hline & \multicolumn{2}{|c|}{$P$} & \multicolumn{2}{|c|}{$\mathrm{PP}$} & \multirow{2}{*}{$\frac{\mathrm{S}}{u}$} \\
\hline & $u$ & $w$ & $u$ & $w$ & \\
\hline Using $Y$, equation (6) & 0.45 & 0.43 & 0.41 & 0.44 & 0.46 \\
\hline Corrected for $T \ldots$ & 0.43 & 0.41 & 0.41 & 0.40 & 0.41 \\
\hline Added station correction.... & 0.40 & 0.40 & 0.38 & 0.38 & 0.40 \\
\hline Added distance correction..... & 0.37 & 0.37 & 0.32 & 0.36 & 0.35 \\
\hline
\end{tabular}

All corrections applied, only special readings for four selected shocke

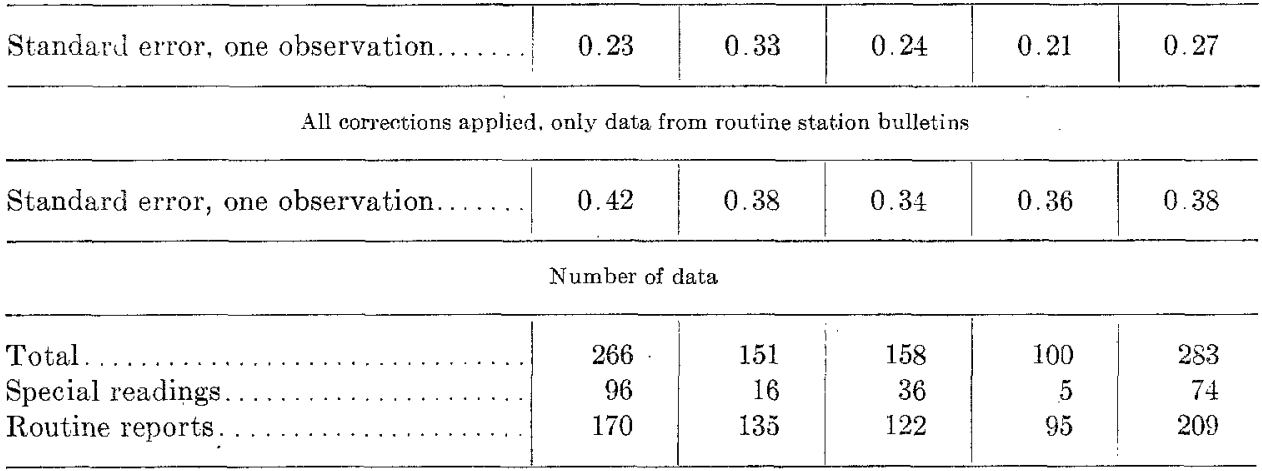

combined. The following are the resulting average residuals, with number of data in parentheses:

Magnitude...................

Residuals, $\mathrm{P}$ and PP.............

6.7 to 6.9

7.0 to 7.3

7.4 to 7.6

7.7 to 8.3

Residuals, $\mathrm{S}$

$+0.09(29)$

$0.00(397)$

$-0.04(88)$

$-0.07(162)$

The plus sign means that the observed amplitudes are greater than the calculated. It appears that the reported amplitudes of $\mathrm{P}$ and $\mathrm{PP}$ increase slightly less with magnitude than is indicated by the simplified theory. To obtain more accurate results, all 675 residuals were analyzed by the method of least squares, supposing a form $a+b(M-7)$. The resulting correction to the values calculated from equation (7) with $C=6.3$ is $(0.03 \pm 0.02)-(0.15 \pm 0.04)(M-7)$. This gives $C=6.33 \pm 0.02$, and a term $-(0.25 \pm 0.04)(M-7)$ instead of $-0.1(M-7)$. The difference is probably a result of the simplification of the theory, especially equation (5). 
TABLE 4

Values of $A=6.3-\log U($ or $6.3-\log W)$ as a Function of the Distance $\Delta$ (in Degrees)

\begin{tabular}{|c|c|c|c|c|c|c|c|c|c|c|c|}
\hline$\Delta$ & 3 & 4 & 5 & 6 & 7 & 8 & 10 & 11 & 13 & 14 & 15 \\
\hline $\begin{array}{l}\text { P horizontal. } \\
\text { P vertical ... }\end{array}$ & 6.0 & 6.3 & 6.6 & 6.9 & $7: 1$ & $7.2 \quad 7$. & 7.3 & $\begin{array}{ll}7.4 & 7 . \\
7 & 7\end{array}$ & $\begin{array}{l}7.4 \\
7.3\end{array}$ & 7.3 & 6.0 \\
\hline \multirow{2}{*}{\multicolumn{6}{|c|}{$\Delta$}} & \multicolumn{2}{|c|}{$P$} & \multicolumn{2}{|c|}{$P P$} & \multicolumn{2}{|c|}{$\mathrm{s}$} \\
\hline & & & & & & Horizontal & Vertical & Horizontal & Vertical & Hori & ontal \\
\hline $\begin{array}{l}16 \ldots \ldots \ldots \\
18 \ldots \ldots \ldots \\
20 \ldots \ldots \\
21-25 \ldots \ldots \\
25-29 \ldots \ldots\end{array}$ & $\begin{array}{l}\ldots \ldots \\
\ldots \ldots \\
\ldots \ldots \\
\ldots \ldots\end{array}$ & $\begin{array}{l}\ldots \ldots \\
\cdots \cdots \\
\cdots \cdots \\
\cdots \cdots\end{array}$ & $\begin{array}{l}\ldots \\
\cdots \\
\cdots \\
\cdots\end{array}$ & $\ldots$ & & $\begin{array}{l}6.2 \\
6.4 \\
6.6 \\
6.7 \\
6.7\end{array}$ & $\begin{array}{l}6.1 \\
6.3 \\
6.4 \\
6.5 \\
6.5\end{array}$ & $\begin{array}{l}\cdots \\
\cdots \\
\cdots \\
\cdots\end{array}$ & $\begin{array}{l}\cdots \\
\cdots \\
\cdots \\
\cdots \\
\cdots\end{array}$ & & $\begin{array}{l}9 \\
9 \\
0 \\
0 \\
1\end{array}$ \\
\hline $\begin{array}{l}29-33 \ldots \ldots \\
33-35 \ldots \ldots \\
35-37 \ldots \ldots \\
37-39 \ldots \ldots \\
39-41 \ldots \ldots\end{array}$ & $\begin{array}{l}\ldots \\
\ldots \\
\ldots \\
\cdots \\
\cdots\end{array}$ & $\begin{array}{l}\ldots \\
\cdots \cdots \\
\cdots \\
\cdots \\
\cdots\end{array}$ & $\begin{array}{l}\ldots \\
\ldots \\
\cdots \\
\cdots \\
\cdots\end{array}$ & $\begin{array}{l}\ldots \\
\ldots \\
\ldots\end{array}$ & $\begin{array}{l}. . \\
. \\
. \\
.\end{array}$ & $\begin{array}{l}6.8 \\
6.8 \\
6.9 \\
6.9 \\
6.9\end{array}$ & $\begin{array}{l}6.6 \\
6.6 \\
6.7 \\
6.7 \\
6.7\end{array}$ & $\begin{array}{l}7.0 \\
7.0 \\
7.0 \\
7.0 \\
6.9\end{array}$ & $\begin{array}{l}6.8 \\
6.8 \\
6.8 \\
6.8 \\
6.7\end{array}$ & & $\begin{array}{l}2 \\
3 \\
4 \\
5 \\
6\end{array}$ \\
\hline $\begin{array}{l}41-42 \ldots \ldots \\
42-49 \ldots \ldots \\
49-51 \ldots \ldots \\
51-53 \ldots \ldots \\
53-57 \ldots \ldots\end{array}$ & $\begin{array}{l}\ldots \\
\ldots \\
\cdots \\
\cdots \\
\cdots\end{array}$ & $\begin{array}{l}\ldots \\
\ldots \ldots \\
\ldots \ldots \\
\ldots \ldots \\
\cdots\end{array}$ & $\begin{array}{l}\ldots \\
\ldots \\
\cdots \\
\ldots \\
\cdots\end{array}$ & $\begin{array}{l}\ldots \\
\ldots \\
\ldots \\
\ldots \\
\ldots\end{array}$ & $\begin{array}{l}\ldots \\
\ldots \ldots \\
\ldots \\
\cdots \\
\cdots \\
\cdots\end{array}$ & $\begin{array}{l}7.1 \\
7.0 \\
7.1 \\
7.1 \\
7.1\end{array}$ & $\begin{array}{l}6.9 \\
6.8 \\
6.8 \\
6.8 \\
6.8\end{array}$ & $\begin{array}{l}6.8 \\
6.8 \\
6.9 \\
7.0 \\
7.1\end{array}$ & $\begin{array}{l}6.6 \\
6.6 \\
6.7 \\
6.8 \\
6.9\end{array}$ & & $\begin{array}{l}6 \\
6 \\
6 \\
5 \\
6\end{array}$ \\
\hline $\begin{array}{l}57-59 \ldots \ldots \\
59-61 \ldots \ldots \\
61-63 \ldots \ldots \\
63-67 \ldots \ldots \\
67-71 \ldots \ldots\end{array}$ & $\begin{array}{l}\cdots \\
\cdots \\
\cdots \\
\cdots \\
\cdots\end{array}$ & $\begin{array}{l}\ldots \ldots \\
\cdots \cdots \\
\cdots \cdots \\
\cdots \cdots\end{array}$ & $\begin{array}{l}\ldots \ldots \\
\ldots \ldots \\
\ldots \ldots \\
\ldots \ldots \\
\ldots \ldots\end{array}$ & $\ldots$ & & $\begin{array}{l}7.1 \\
7.1 \\
7.2 \\
7.1 \\
7.2\end{array}$ & $\begin{array}{l}6.8 \\
6.9 \\
6.9 \\
6.8 \\
6.8\end{array}$ & $\begin{array}{l}7.2 \\
7.3 \\
7.3 \\
7.3 \\
7.2\end{array}$ & $\begin{array}{l}7.0 \\
7.0 \\
7.1 \\
7.1 \\
7.0\end{array}$ & & $\begin{array}{l}7 \\
.8 \\
.9 \\
0 \\
.8\end{array}$ \\
\hline $\begin{array}{l}71-73 \ldots \ldots \\
73-75 \ldots \ldots \\
75-77 \ldots \ldots \\
77-79 \ldots \ldots \\
79-81 \ldots \ldots\end{array}$ & $\begin{array}{l}\ldots \ldots \\
\ldots \ldots \\
\cdots \cdots \\
\cdots \cdots \\
\cdots \cdots\end{array}$ & $\begin{array}{l}\ldots \ldots \\
\ldots \cdots \\
\cdots \cdots \\
\cdots \cdots \\
\cdots \cdots\end{array}$ & $\begin{array}{l}\ldots \\
\ldots \\
\cdots \\
\cdots \\
\cdots\end{array}$ & $\begin{array}{l}\cdots \\
\cdots \\
\cdots \\
\cdots\end{array}$ & $\begin{array}{l}\ldots \\
\cdots \\
\cdots \\
\cdots \\
\cdots \\
\cdots\end{array}$ & $\begin{array}{l}7.3 \\
7.3 \\
7.3 \\
7.2 \\
7.1\end{array}$ & $\begin{array}{l}6.9 \\
6.9 \\
7.0 \\
6.8 \\
6.7\end{array}$ & $\begin{array}{l}7.3 \\
7.2 \\
7.2 \\
7.2 \\
7.2\end{array}$ & $\begin{array}{l}7.0 \\
7.0 \\
7.0 \\
7.0 \\
7.0\end{array}$ & & $\begin{array}{l}1 \\
9 \\
.8 \\
9 \\
9\end{array}$ \\
\hline $\begin{array}{l}81-83 \ldots \ldots \\
83-85 \ldots \ldots \\
85-87 \ldots \ldots \\
87-89 \ldots \ldots \\
89-91 \ldots \ldots\end{array}$ & $\begin{array}{l}\ldots \ldots \\
\ldots \ldots \\
\ldots \ldots \\
\cdots \cdots\end{array}$ & $\begin{array}{l}\ldots \\
\cdots \\
\ldots \\
\cdots \\
\cdots\end{array}$ & $\begin{array}{c}\cdots \\
\cdots \\
\cdots\end{array}$ & $\cdots$ & $\begin{array}{l}\cdots \\
\cdots \\
\cdots \\
\cdots \\
\cdots\end{array}$ & $\begin{array}{l}7.3 \\
7.4 \\
7.5 \\
7.5 \\
7.3\end{array}$ & $\begin{array}{l}6.8 \\
6.9 \\
7.0 \\
7.0 \\
6.8\end{array}$ & $\begin{array}{l}7.5 \\
7.4 \\
7.4 \\
7.4 \\
7.3\end{array}$ & $\begin{array}{l}7.3 \\
7.2 \\
7.2 \\
7.1 \\
7.0\end{array}$ & & $\begin{array}{l}0 \\
9 \\
.8 \\
9 \\
.0\end{array}$ \\
\hline $\begin{array}{r}91-95 \ldots \ldots \\
95-97 \ldots \ldots \\
97-99 \ldots \ldots \\
99-103 \ldots \ldots \\
103-105 \ldots \ldots\end{array}$ & $\begin{array}{l}\ldots \\
\cdots \\
\cdots \\
\cdots \\
\cdots \\
\cdots\end{array}$ & $\begin{array}{l}\ldots \\
\ldots \\
\ldots \\
\ldots \\
\ldots\end{array}$ & $\begin{array}{l}\cdots \\
\cdots \\
\cdots\end{array}$ & 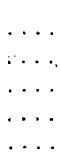 & & $\begin{array}{l}7.2 \\
7.6 \\
7.8 \\
8.0 \\
8.0\end{array}$ & $\begin{array}{l}6.8 \\
7.2 \\
7.3 \\
7.4 \\
7.4\end{array}$ & $\begin{array}{l}7.2 \\
7.2 \\
7.2 \\
7.3 \\
7.5\end{array}$ & $\begin{array}{l}6.9 \\
6.9 \\
6.9 \\
7.0 \\
7.1\end{array}$ & & $\begin{array}{l}.0 \\
1 \\
.2 \\
.2 \\
.2\end{array}$ \\
\hline $\begin{array}{l}105-111 \ldots \ldots \\
111-114 \ldots \ldots \\
114-118 \ldots \ldots \\
118-125 \ldots \ldots \\
125-129 \ldots \ldots\end{array}$ & $\begin{array}{l}\cdots \\
\cdots \\
\cdots \\
\cdots \\
\cdots \\
\cdots\end{array}$ & $\ldots$ & . & & & $\begin{array}{l}\cdots \\
\cdots \\
\cdots \\
\cdots \\
\cdots\end{array}$ & $\begin{array}{l}\cdots \\
\cdots \\
\cdots \\
\ldots \\
\ldots\end{array}$ & $\begin{array}{l}7.5 \\
7.6 \\
7.5 \\
7.4 \\
7.3\end{array}$ & $\begin{array}{l}7.2 \\
7.2 \\
7.2 \\
7.1 \\
7.0\end{array}$ & & $\begin{array}{l}\ldots \\
\ldots \\
\ldots \\
\ldots\end{array}$ \\
\hline $\begin{array}{l}129-137 \ldots \ldots \\
137-144 \ldots \ldots \\
144-149 \ldots \ldots \\
149-157 \ldots \ldots \\
157 \ldots \ldots \ldots\end{array}$ & $\begin{array}{l}\ldots \\
\cdots \cdots \\
\cdots \\
\cdots \\
\cdots \cdots\end{array}$ & $\ldots$ & . & & & $\begin{array}{l}\cdots \\
\cdots \\
\cdots \\
\cdots \\
\cdots\end{array}$ & $\begin{array}{l}\cdots \\
\cdots \\
\cdots \\
\cdots\end{array}$ & $\begin{array}{l}7.4 \\
7.5 \\
7.4 \\
7.3 \\
7.4\end{array}$ & $\begin{array}{l}7.0 \\
7.1 \\
6.9 \\
6.8 \\
6.9\end{array}$ & & $\begin{array}{l}\cdots \\
\cdots \\
. \\
.\end{array}$ \\
\hline
\end{tabular}


There is no clear similar trend of the residuals of $\mathrm{S}$. The method of least squares applied to the 283 residuals, proceeding exactly as for $\mathrm{P}$, gives the correction

$$
(-0.01 \pm 0.03)-(0.04 \pm 0.06)(M-7)
$$

and $C=6.29 \pm 0.03$, with $-(0.14 \pm 0.06)$ as coefficient of $(M-7)$.

For practical purposes, at present it seems best to use equation (7) in the determination of magnitudes, except for $\mathrm{P}$ and $\mathrm{PP}$ in shocks below magnitude $6 \frac{1}{2}$ or over $71 / 2$ where equation ( 7 ) should be replaced tentatively by

$$
C=Y-1 / 4(M-7)+\log T
$$

Table 3 gives a summary of the standard errors for one observation which were encountered during the various steps of the calculations (not including corrections for $M$ in $\mathrm{P}$ and $\mathrm{PP}$ ). They contain errors in the determination of the magnitude $M$, the distance $\Delta$ and its function $U$, and the period $T$, aside from those in the reported amplitudes. The last two groups of the table show that one reading based on a special study of original seismograms in the four shocks mentioned should have been given about twice the weight of a routine reading reported in a station bulletin. However, this is not generally true for any one special original reading, for in the four shocks with special readings the distances were much better determined than for a shock used in routine, and many more data for the maximum amplitudes were available to find magnitudes for these four shocks. Based on the present investigation, it is the judgment of the author that the combined use of two well-recorded body waves out of the three discussed here will give about the same accuracy in the resulting magnitude as the use of the maximum of surface waves with a period of about 20 seconds.

Table 4 gives $A=6.3-\log U$ (or $6.3-\log W$ ) as a function of $\Delta$. For distances between $6^{\circ}$ and $15^{\circ}, \mathrm{P}$ and $\mathrm{S}$ are very small; $\mathrm{P}$ is generally recorded only in shocks of magnitude 7 or more; $S$ rarely if ever can be identified with confidence. The figures given at the beginning of table 4 are based on data from southern California earthquakes (Gutenberg, 1944b), original records of the Montana earthquakes of October 19 and 31 (G.C.T.), 1935, at stations of the Pasadena group, data discussed by Gutenberg (1926), and a few other shocks; they are less accurate than those for $\Delta>18^{\circ}$ and depend more on the depth of focus. The values of $A$ in table 4 together with the observed ground amplitudes in microns (total horizontal $u$, vertical $w$, considering the station corrections given in table 2 ) and their periods $T$ give the magnitude $M$ of shallow shocks from equation (9):

$$
M=A+0.1(M-7)-\log T+\log u(\text { or } \log w)
$$

with a tentative additional correction of $+0.1(M-7)$ f for all longitudinal waves in great shocks or shocks of magnitude less than $61 / 2$.

In investigating the seismicity of the earth, Gutenberg and Richter (1941, p. 2) set up arbitrary classes for shallow shocks as follows: class $e$, shocks for which $\mathrm{P}$, in general, is not reported beyond $10^{\circ}$; class $d$, to about $45^{\circ}$; class $c$, to about $90^{\circ}$; class $b$, at all stations. Empirically these classes were identified with the following corresponding ranges of magnitude:
Class $b$
$7-7.7$ ${ }^{c}-7$ $5.3-6$ $<5.3$ 
These values can now be calculated. The average period of $\mathrm{P}$ waves in teleseisms is about 4 to 6 seconds; the instrumental magnification for waves with these periods at most stations (which were used in estimating $M$ ) is about 100 to 150 ; the minimum ground amplitude of a $\mathrm{P}$ wave for which the time is regularly reported is about $1 / 2$ micron (corresponding to range of the trace amplitude of $0.1 \mathrm{~mm}$.). Introducing these values in equation (18), we find approximately $M=A-1$ for the minimum magnitude for which $\mathrm{P}$ waves are generally reported. For shocks of class $d, A$ depends appreciably on the distance of the nearest stations (table 4); if stations with distances near $16^{\circ}$ are available, $M$ may be as small as 5 ; if the nearest stations beyond $\Delta=14^{\circ}$ are at a distance of $20^{\circ}$ or more, $M$ must be at least $5 \% / 4$. For a shock with $\mathrm{P}$ recorded generally beyond $45^{\circ}, A$ is greater than 7 and $M$ must be at least 6 . For shocks with $\mathrm{P}$ generally recorded at distances out to the limit of its occurrence $A$ is 8 and $M$ must be at least 7 . All calculated values agree with the empirical results.

It would be very desirable to compare for a number of shocks the magnitude as determined by the original method of Richter from records of near-by stations in southern California with values calculated from $\mathrm{P}, \mathrm{PP}$, or $\mathrm{S}$ waves at distant stations, using equation (18). Unfortunately, in general either the shocks are too small to record with $\mathrm{P}$ and $\mathrm{S}$ at distant stations, or too large to furnish a complete record at the near-by stations. The only useful instances of this kind were as follows. The Long Beach earthquake of March 11, 1933 (G.C.T.), was recorded at La Paz $\left(\Delta=69^{\circ}\right)$ with a horizontal ground amplitude of 4 microns in the $\mathrm{S}$ wave $(T=10$ sec.). This gives $M=6.5$ as compared with 6.3 from some of the California stations. The ground movements produced by the Imperial Valley earthquake of May 18, 1940, were reported by La Paz as follows: P vertical 2 microns $(T=4)$ and also 5 $(T=7)$; PP vertical 11/2 $(T=8)$ and S horizontal $2(T=13)$; the magnitudes calculated from these are, respectively, $6.8 ; 6.8 ; 6.7$ and 6.4 . California stations gave an average of 6.7 . The earthquake of December 31, 1934, had too large amplitudes on all near-by torsion seismographs to be completely recorded; the Pasadena strongmotion seismograph showed a trace maximum of $6 \mathrm{~mm}$, corresponding to a magnitude of 7.2; surface waves at distant stations gave 7.0, and six amplitudes of P, PP, and $\mathrm{S}$ at La Paz, Jena, and Cartuja gave $7.0 \pm 0.2$.

The amplitudes of $\mathrm{P}, \mathrm{PP}$, and $\mathrm{S}$ cannot be used in the determination of the magnitude of intermediate or deep shocks without additional definition and further investigations (which are now in progress). However, they give better results than the use of surface-wave amplitudes when the depth of focus is between about 30 and $70 \mathrm{~km}$. An example is the South German earthquake of 1911 (Gutenberg, 1915). From the radius of the area of perceptibility and the maximum intensity, Gutenberg and Richter (1942, p. 181) found the logarithm of the energy in ergs to be 22; for a shallow shock this would correspond to a magnitude of $6 \frac{1}{2}$ (eq. 4 ). On the other hand, the surface waves recorded at Pulkovo and Baku gave a magnitude of only 5.5 and 5.2, respectively, which is definitely too small for this shock. Amplitudes of $P$ at six stations, using the approximate values for $\log U$ at distances between 262 and $462 \mathrm{~km}$., as well as $\mathrm{P}$ at Baku $\left(\Delta=30^{\circ}\right)$, give $M=6.3 \pm 0.2$.

Amplitudes of $P, P P$, and $S$ may also be useful in the determination of the magnitude of great shocks, when the maxima of the surface waves are too large to be fully 
recorded. In such instances the maximum of $\mathrm{P}, \mathrm{PP}$, or $\mathrm{S}$ should be used. Readings from the reproduced seismograms of the San Francisco earthquake of 1906 gave the following results (five stations each for $\mathrm{P}, \mathrm{PP}$, and $\mathrm{S} ; \mathrm{P}$ and $\mathrm{PP}$ corrected as indicated by eq. 17):

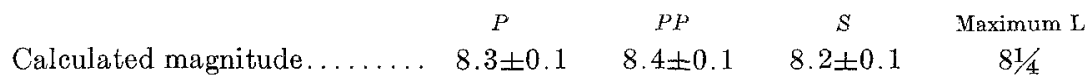

For the Kansu earthquake of December 16, 1920, seismograms published by Hecker and Sieberg at Jena, 1921, lead to the following magnitudes: from P (four stations), $8.3 \pm 0.1$; from two values of $\mathrm{PP}, 8.3$; from eight values of $\mathrm{S}, 8.3 \pm 0.1$. The surface waves gave $81 / 2$. The agreement supports the preference of equation (17) over equation (7) for longitudinal waves in great earthquakes.

The author is grateful to Dr. C. F. Richter and to Mr. H. O. Wood for valuable criticism.

\section{Summary}

It is found that the absorption coefficient for longitudinal and transverse waves in the mantle of the earth as well as for longitudinal waves through the core is 0.00012 per $\mathrm{km}$. In the average shallow earthquake about equal amounts of energy go into longitudinal and transverse waves. Equation (18), together with tables 2 and 4, permits the calculation of the magnitude of a shallow earthquake from the amplitudes of P, PP, or S. 


\section{References}

BYERLY, P.

1926. "The Montana Earthquake of June 28, 1925," Bull. Seism. Soc. Am., 16:209-265.

DANA, S. W.

1944. "The Amplitudes of Seismic Waves Reflected and Refracted at the Earth's Core,", thesis for the Ph.D. degree, California Institute of Technology, Pasadena, Calif.; published in briefer form, Bull. Seism. Soc. Am., 35:27-35 (1945).

Geiger, L., and B. Gutenberg

1912. "Ueber Erdbebenwellen. VI," Nachr. k. Ges. d. Wiss. z. Göttingen, math.-phys. Kl., pp. 623-675.

Gutenberg, B.

1915. "Die mitteleuropäischen Beben vom 16. November 1911 und vom 20. Juli 1913," Veröff. Zentralbureau der Internat. Seism. Assoz., 84 pages and 32 plates.

1925. "Bearbeitung von Aufzeichnungen einiger Weltbeben," Abh. der Senckenberg. Naturforsch. Gesell., 40:57-88.

1944a. "Energy Ratio of Reflected and Refracted Seismic Waves," Bull. Seism. Soc. Am.; $34: 85-102$.

1944b. "Reflected and Minor Phases in Records of Near-by Earthquakes in Southern California," Bull. Seism. Soc. Am., 34:137-160.

1945. "Amplitudes of Surface Waves and Magnitude of Earthquakes," Bull. Seism. Soc. Am., $35: 3-12$.

Gutenberg, B., and C. F. Rxchter

1939. "On Seismic Waves (Fourth Paper)," Gerlands Beitr. z. Geophysik, 54:94-136.

1941. "Seismicity of the Earth," Geol. Soc. Am., Special Papers, No. 34.

1942. "Earthquake Magnitude, Intensity, Energy, and Acceleration," Bull. Seism. Soc. Am., 32:163-191.

JEFFREYS, H.

1936. "The Structure of the Earth Down to the $20^{\circ}$ Discontinuity," Mon. Not. Roy. Astron. Soc., Geophys. Suppl., 3:401-422.

1937. "The Structure of the Earth Down to the $20^{\circ}$ Discontinuity (Second Paper)," Mon. Not. Roy. Astron. Soc., Geophys. Suppl., 4:13-39.

Maceldane, J. B.

1923. "A Study of the Relation between the Periods of Elastic Waves and the Distance Traveled by Them, Based upon the Seismographic Records of the California Earthquake, January 31, 1922," Bull. Seism. Soc. Am., 13:13-69.

REID, H. F.

1910. "The California Earthquake of April 18, 1906." Carnegie Inst. of Washington, Publ. 87, Vol. II, Pt. II:59-142, and Atlas (1908) with 15 plates of seismograms.

SOMMER, H.

1931. "On the Question of Dispersion in the First Preliminary Seismic Waves," Bull. Seism. Soc. Am., 21:87-158.

Zoeppritz, K., L. Geiger, and B. Gutenberg

1912. "Ueber" Erdbebenwellen. V," Nachr. k. Ges. d. Wiss. z. Göttingen, math.-phys. Kl., pp. 121-206.

California Institute of Technology, Pasadena, California

(Balch Graduate School of the Geological Sctences, Contribution No. 377) 